\title{
Comparative Study of Novel Tubular Flux-Reversal Transverse Flux Permanent Magnet Linear Machine
}

\author{
Shaohong Zhu ${ }^{1,2}$, Tom $\operatorname{Cox}^{1,2}$, and Chris Gerada ${ }^{1,2}$ \\ ${ }^{1}$ Institute for Aerospace Technology, University of Nottingham, Nottingham, UK \\ ${ }^{2}$ Department of Electrical and Electronic Engineering, University of Nottingham, Nottingham, UK \\ shaohong.zhu@nottingham.ac.uk
}

\begin{abstract}
This paper presents a novel tubular flux-reversal transverse flux permanent magnet linear machine (FRTFPMLM), in which both magnet and armature winding are located at the short primary side whereas the secondary side is composed of only magnetic steel. This configuration is typically used in long stroke applications to save magnet material. With different configurations of phase winding, the machine can have two topologies, viz. axial three-phase and circumferential threephase. The structure and operational principle of both topologies are firstly introduced; And then both theoretical and numerical analyses are performed. The electromagnetic characteristics of both machines, with particular focus on thrust force and force ripple, are optimized. Finally, the performances of optimal schemes of these two topologies are summarized and compared.
\end{abstract}

Keywords-flux-reversal; linear machine; permanent magnet; thrust force; transverse flux

\section{INTRODUCTION}

Linear machines with Permanent Magnet (PM) excitation have been increasingly used in various applications including actuation systems [1], domestic appliances [2] and electromagnetic launchers [3] due to their excellent dynamic servo characteristics, high speed and high positional accuracy [4, 5]. Linear machines can be classified by their magnetic circuit as two distinct types: longitudinal flux and transverse flux. Three types of longitudinal flux permanent magnet linear machine, including radial magnetization, axial magnetization, and Halbach magnetization, have been studied by J.B. Wang, et al. [5-7], including theoretical analysis and experimental work. For the transverse flux linear machine, a number of topologies have also been proposed in recent years due to the configurations high force density $[8,9]$.

However, such types of machine with PMs located on a long secondary result in significant costs due to the significant volume and high cost of magnetic materials needed. Therefore, machines with PMs located at the short primary become the focus of the research, since this can be a cost effective solution for long stroke applications $[10,11]$. These primary-PM motors can be divided into three types based on the location of PM in the primary, viz., doubly salient PM (DSPM) motor, flux switching PM (FSPM) motor, and flux-reversal PM (FRPM) motor. The DSPM motor can be recognized as a switched reluctance (SR) motor with $\mathrm{PM}$ in the stator to provide a magnetic field, in which the flux linkage is unipolar and the torque/force production of this motor can be greatly enhanced compared with a reluctance motor [10]. The FSPM motor is a motor with PMs sandwiched in the primary teeth. When the rotor is aligned with different primary teeth, the PM magnets will change flux path, so that a bipolar flux linkage can be obtained. The FRPM motor has PM magnets placed on the surface of the primary teeth, and is similar to a surface-mounted PM motor. However, the biggest challenge for this motor is the demagnetization risk to the magnets since the armature field is directly in series with the magnetization direction of the PMs [12], and this type can also exhibit large flux leakage.

This paper presents a tubular flux-reversal transverse flux permanent magnet linear machine (FR-TFPMLM), in which both PMs and armature windings are located at short primary side while the secondary side is composed of only magnetic steel. This configuration can save PM material and so is potentially useful for long-stroke applications. The proposed FR-TFPMLM can have two topologies via different configurations of phase winding: axial three-phase and circumferential three-phase, as shown in Fig. 1. Both theoretical analysis and numerical calculation of these two topologies of machine are studied. The electromagnetic characteristics, including flux linkage, back electromotive force and thrust force, are presented. Finally, the performances of optimal schemes of these two topologies are summarized and compared.

\section{MODELS AND OPERATIONAL PRINCIPLE}

\section{A. Models of FR-TFPMLM}

The FR-TFPMLM can have two kinds of structure via different configurations of phase winding, viz. axial three-phase structure and circumferential three-phase structure, as shown in Fig. 1(a) and (b), separately. For the axial three-phase FRTFPMLM, adjacent phases are arranged by $(2 k-2 / 3)$ pole pitch displacement in axial direction, where $k$ is a non-negative integer. The circumferential three-phase FR-TFPMLM, in which the three phase windings are located around the circumference of primary, is realized by $2 / 3$ pole pitch displacement of the secondary side tooth of each phase in the axial direction. These two topologies have the same primary side structure, which is composed by generic armature cores and with PMs located at the surface of teeth but PMs under adjacent poles having opposite magnetization directions, as shown in Fig 2. Fig 3(a) and (b) show the long secondary side of the axial and circumferential three-phase configuration, respectively, both of which are only composed of magnetic steel and could be made by silicon-iron laminations. 

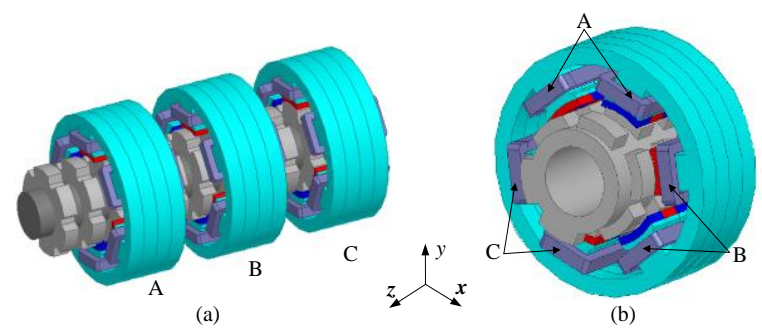

Fig. 1 Overall structure (a) Axial three-phase FR-TFPMLM (b) Circumferential three-phase FR-TFPMLM

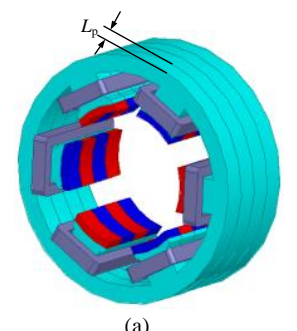

(a)

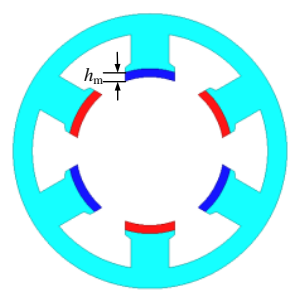

(b)

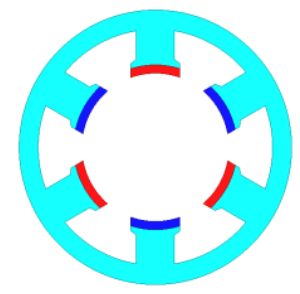

(c)
Fig. 2 Primary side of two pole pairs (a) 3-D view (b) Cut view of P pole (c) Cut view of $\mathrm{P}+1$ pole.

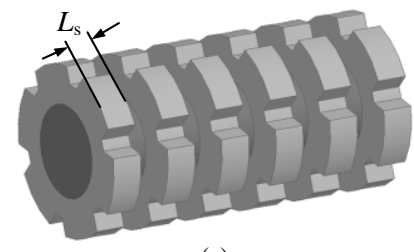

(a)

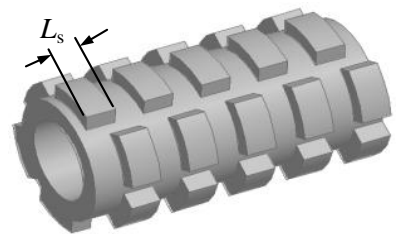

(b)
Fig. 3 Secondary side (a) Axial three-phase FR-TFPMLM (b) Circumferential three-phase FR-TFPMLM

With PMs located at the short primary side, the FRTFPMLM is suitable for long-stroke application. Both the armature cores and secondary side core can be made of unsegmented silicon-iron lamination, which simplifies the manufacturing and improves the stiffness of the machine compared to conventional transverse flux machine. For the axial three-phase FR-TFPMLM, the magnetic circuit is symmetric, indicating that there is no unbalanced magnetic force on the linear bearing. The circumferential three-phase FR-TFPMLM will experience unbalanced magnetic force, unless the machine contains $12 i$ slots, where $i$ is a non-negative integer.

\section{B. Operational Principle}

Taking the axial three-phase FR-TFPMLM as an example to introduce the operational principle of the machine, when the long secondary side teeth align with the $P$ pole at the initial position $\theta=0^{0}$, flux linkage induced in the coils for this position is defined as positive maximum, as shown in Fig 4(a), which shows the main magnetic flux flow from $\mathrm{S}$ magnet to the teeth of primary iron core, and then the yoke; The flux path then passes through another transversely adjacent tooth of the primary core, crossing the $\mathrm{N}$ magnet and airgap, and finally returning to initial magnet via the secondary side iron core and airgap. At position $\theta=180^{\circ}$, the primary side moves to the position that secondary side teeth align with $P+1$ pole, as shown in Fig.4 (b), in which the flux linkage induced in the coils reaches its negative maximum value. Hence, bipolar flux linkage will be induced in the coils when the primary side moves along the z-direction.

Fig.5 shows the side view of the axial three-phase FRTFPMLM at one position. As we can see, the armature flux is generated by feeding the coils with a constant current, and its direction is opposite to the $\mathrm{N}$ pole magnets while the same as the $\mathrm{S}$ pole magnets, so the primary side will move to find a position where the primary side is over the secondary side and the flux produced by the PMs and the armature field will have the same direction. An inversion of the excitation current will change the direction of the movement. As a result, a constant longitudinal force will be generated when the armature winding is fed with an appropriate alternating current.

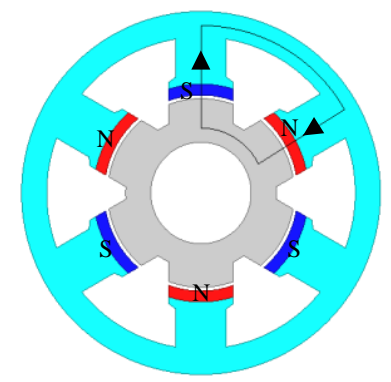

(a)

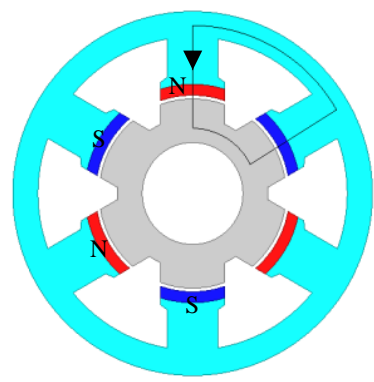

(b)
Fig. 4 Flux path of the axial three-phase FR-TFPMLM. (a) Positive maximum ( $\mathrm{P}$ pole) (b) Negative maximum $(\mathrm{P}+1$ pole)

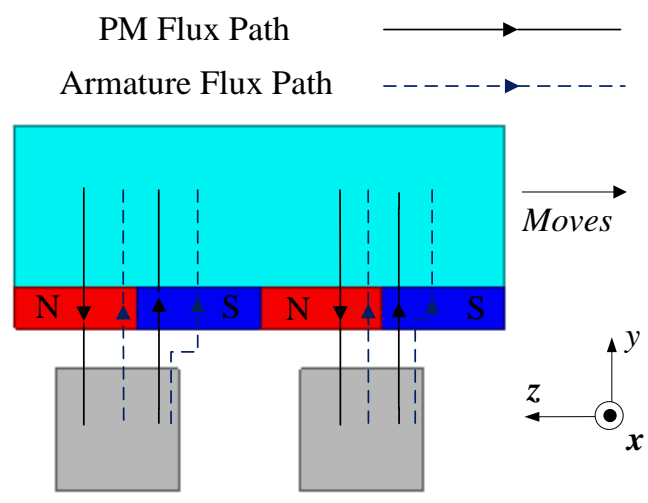

Fig. 5 Side view of axial three-phase FR-TFPMLM

\section{ANALYSIS OF AXIAL THREE-PHASE FR- TFPMLM}

\section{A. Theoretical Analysis of Electromagnetic Force}

The value and direction of the main magnetic flux will vary with the displacement when the primary moves, hence the expression of per pole pair no-load main magnetic flux can be written as

$$
\left.\varnothing=\emptyset_{m} \cos \left(\frac{z}{\tau} \pi\right)\right)
$$

where $\emptyset_{m}$ is the magnitude of no-load main magnetic flux and $z$ is the displacement. 
If the number of turns of each winding and each pole pair is $N$ and $p$ respectively, the no-load back electromotive force (EMF) can be expressed as

$$
\left.\left.e=-N \frac{d \emptyset}{d t}=2 \pi f N p \emptyset_{m} \sin \left(\frac{z}{\tau} \pi\right)\right)\right)
$$

If the winding is fed with an alternating current, and $\mathrm{I}_{\mathrm{d}}=0$ control method is adopted, based on the principle of power conversion balance, the thrust force of one phase of the FRTFPMLM can be written as in (3). It should be noted that both core loss and mechanical loss are neglected here.

$$
\begin{aligned}
F=\frac{e i}{v} & =\frac{2 \pi f N p \emptyset_{m} \sin \left(\frac{z}{\tau} \pi\right) * I_{m} \sin \left(\frac{z}{\tau} \pi\right)}{2 f \tau} \\
& =\frac{\pi N p \emptyset_{m} I_{m}}{2 \tau}\left(1-\cos \left(2 \frac{z}{\tau} \pi\right)\right)
\end{aligned}
$$

Therefore, when each phase is fed with an appropriate alternating current, the thrust force of per-phase FR-TFPMLM can be presented as

$$
\begin{gathered}
F_{A}=\frac{\pi N p \emptyset_{m} I_{m}}{2 \tau}\left(1-\cos \left(2 \frac{z}{\tau} \pi\right)\right) \\
F_{B}=\frac{\pi N p \emptyset_{m} I_{m}}{2 \tau}\left(1-\cos \left(2\left(\frac{z}{\tau} \pi-\frac{2}{3} \pi\right)\right)\right. \\
F_{C}=\frac{\pi N p \emptyset_{m} I_{m}}{2 \tau}\left(1-\cos \left(2\left(\frac{z}{\tau} \pi-\frac{4}{3} \pi\right)\right)\right.
\end{gathered}
$$

As a result, the thrust force of total three-phase FRTFPMLM is

$$
F_{A}=F_{A}+F_{B}+F_{C}=\frac{3 \pi N p \emptyset_{m} I_{m}}{2 \tau}
$$

It can be observed that the total thrust force is constant and its magnitude is triple of that of one phase. Hence, the feasibility of the approach that one phase of the FR-TFPMLM is chosen to investigate the performance of the machine is confirmed.

Then, the force density of the three-phase FR-TFPMLM can be written as:

$$
f=\frac{F}{V}=\frac{3 \pi N \emptyset_{m} I_{m}}{\pi D_{0}^{2} \tau^{2}}
$$

It can be seen that the force density of the machine is inversely proportional to the pole pitch because the $\emptyset_{m}$ in the numerator is proportional to pole pitch and there is an item $\tau^{2}$ in the denominator, indicating that the force density of the machine can be enlarged by decreasing the pole pitch or increasing the number of pole pairs for a given geometrical dimension.

\section{B. Numerical Calculation of Electromagnetic Force}

In this section, the FR-TFPMLM with axial three-phase configuration will be further studied by using 3-D finite element method (3-D FEM). In order to save computation time, the model of one phase of axial three-phase FR-TFPMLM that includes one pole pair is established based on the decoupling of the magnetic field of three phases. The main design dimensions of the FR-TFPMLM with axial three-phase configuration is shown in Table I.

\section{Influence of Key Design Parameters}

Fig. 6 shows the thrust force and force ripple of axial threephase FR-TFPMLM as a function of axial length of the primary core $L_{p}$ when axial length of secondary core $L_{s}$ is $4 \mathrm{~mm}$ and PM magnetization length $h_{m}$ is $2 \mathrm{~mm}$. As we can see, the thrust force increases nearly proportionally with $L_{p}$, which is reasonable as the increase of $L_{p}$ will also increase the surface area of magnet, which consequently increases the machine magnetic loading. The force ripple decreases when $L_{p}$ is changing from $5 \mathrm{~mm}$ to $7 \mathrm{~mm}$, and then increases with the increase of $L_{p}$. A relatively large thrust force and minimum force ripple can be achieved when $L_{p}$ is $7 \mathrm{~mm}$.

Fig.7 describes the thrust force and force ripple of axial three-phase FR-TFPMLM as a function of axial length of the secondary core $L_{s}$ when $L_{p}$ is $7 \mathrm{~mm}$ and $h_{m}$ is $2 \mathrm{~mm}$. The thrust force does not keep increasing with the length but has an optimal point due to axial flux leakage increasing with the length. Force ripple is variable when $L_{s}$ increases, with the minimum force ripple obtained when $L_{s}$ is $3 \mathrm{~mm}$ or $9 \mathrm{~mm}$. so $L_{s}$ of $4 \mathrm{~mm}$ is chosen to obtain a larger force and lower force ripple.

Fig. 8 shows the thrust force and force ripple of axial threephase FR-TFPMLM as a function of PM magnetization length $h_{m}$. It should be firstly noted that the winding turn number is decreasing with the increase in $h_{m}$ which is due to the reducing slot area, as shown in Table II. The thrust force has a maximum

\begin{tabular}{|c|c|c|c|}
\hline Parameters & Data & Parameters & Data \\
\hline $\begin{array}{c}\text { Stator outer } \\
\text { diameter }\left(D_{o}\right)\end{array}$ & $100 \mathrm{~mm}$ & Pole pitch $(\tau)$ & $9 \mathrm{~mm}$ \\
\hline $\begin{array}{c}\text { Stator inner } \\
\text { diameter }\left(D_{i}\right)\end{array}$ & $52 \mathrm{~mm}$ & Air-gap length $(g)$ & $1 \mathrm{~mm}$ \\
\hline $\begin{array}{l}\text { Axial length of } \\
\text { primary core }\left(L_{p}\right)\end{array}$ & Variable & $\begin{array}{l}\text { Pole pairs number } \\
\text { per phase }(p)\end{array}$ & 2 \\
\hline $\begin{array}{l}\text { PM magnetization } \\
\text { length }\left(h_{m}\right)\end{array}$ & Variable & Rated current & $4 \mathrm{~A}$ \\
\hline $\begin{array}{c}\text { Axial length of } \\
\text { secondary } \operatorname{core}\left(L_{\mathrm{s}}\right)\end{array}$ & Variable & Speed $(v)$ & $1 \mathrm{~m} / \mathrm{s}$ \\
\hline Note & Material & Note & Material \\
\hline Magnet & $\begin{array}{c}\mathrm{N} 35 \mathrm{SH} \\
(\mathrm{Br}: 1.23 \mathrm{~T})\end{array}$ & Iron core & DW315-50 \\
\hline
\end{tabular}
value when $h_{m}$ is $2 \mathrm{~mm}$, and then decreases when $h_{m}$ increases. Two fluctuations are found in force ripple when $h_{m}$ increases, with a minimum force ripple obtained when $h_{m}$ is at $3 \mathrm{~mm}$. Therefore, with consideration of demagnetization risk, a $h_{m}$ of $2 \mathrm{~mm}$ is chosen to obtain a larger thrust force and a lower force ripple at the same time.

TABle I MAIN DESIGN DIMENSIONS OF AXIAL THREE-PHASE FR-TFPMLM

TABLE II WINDING TURN NUMBERS PER SLOT

\begin{tabular}{cccccccc}
\hline \hline$h_{\mathrm{m}}(\mathrm{mm})$ & 1.5 & 2 & 2.5 & 3 & 3.5 & 4 & 4.5 \\
\hline $\mathrm{N}$ & 106 & 105 & 104 & 102 & 100 & 97 & 94 \\
\hline
\end{tabular}




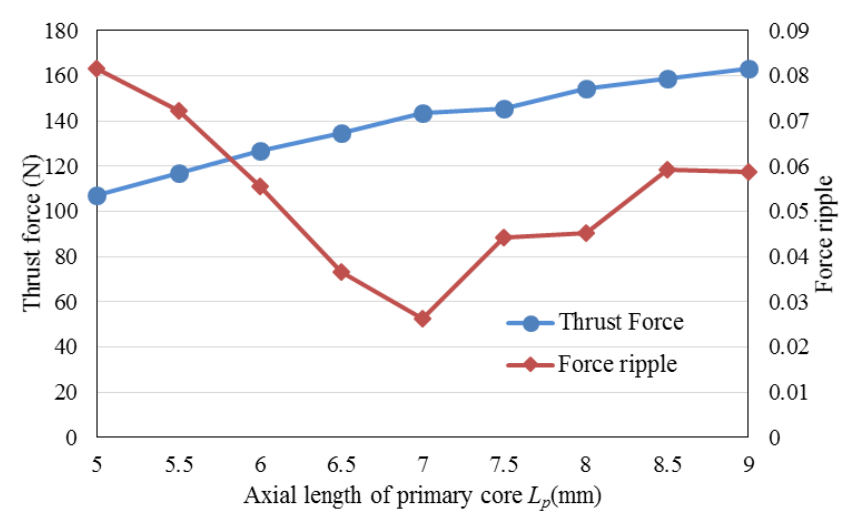

Fig. 6 Thrust force and force ripple of axial three-phase FR-TFPMLM as a function of $L_{\mathrm{p}}$

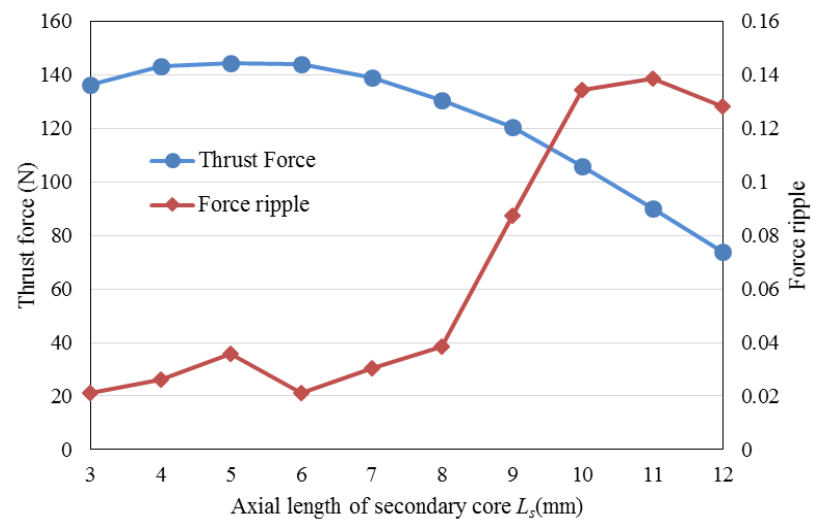

Fig. 7 Thrust force and force ripple of axial three-phase FR-TFPMLM as a function of $L$

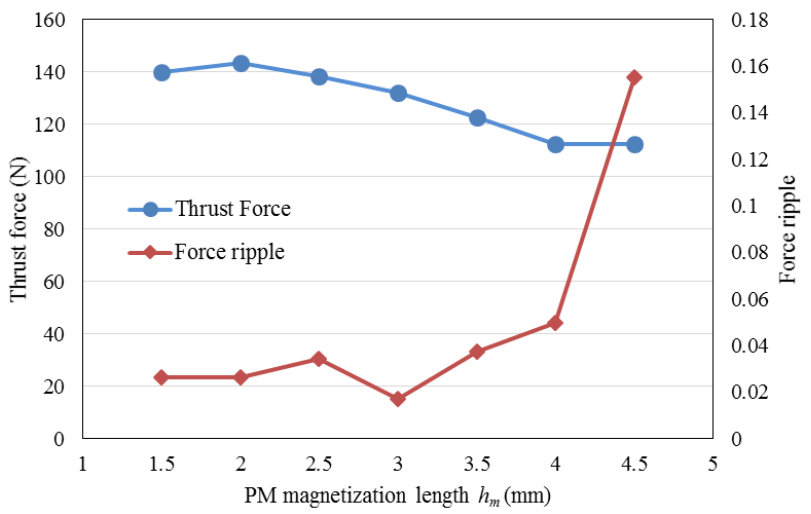

Fig. 8 Thrust force and force ripple of axial three-phase FR-TFPMLM as a function of $h_{m}$

\section{ANALYSIS OF CIRCUMFERENTIAL THREE-PHASE FR- TFPMLM}

\section{A. Theoretical Analysis of Electromagnetic Force}

The theoretical analysis of electromagnetic force of the circumferential three-phase FR-TFPMLM is the same as that of the FR-TFPMLM with axial three-phase configuration except for the different configuration of the three phases.

\section{B. Numerical Calculation of Electromagnetic Force}

Similarly, the model of circumferential three-phase FRTFPMLM with one pole pair is adopted for numerical analysis to save computation time. Design dimensions of these two machines are the same, as shown in Table I except for the pole pair numbers per phase. For circumferential three-phase FRTFPMLM the pole pair number is 6 while for axial three-phase FR-TFPMLM it is 2 , but the overall number of pole pairs for these two machines are the same.

\section{Influence of Key Design Parameters}

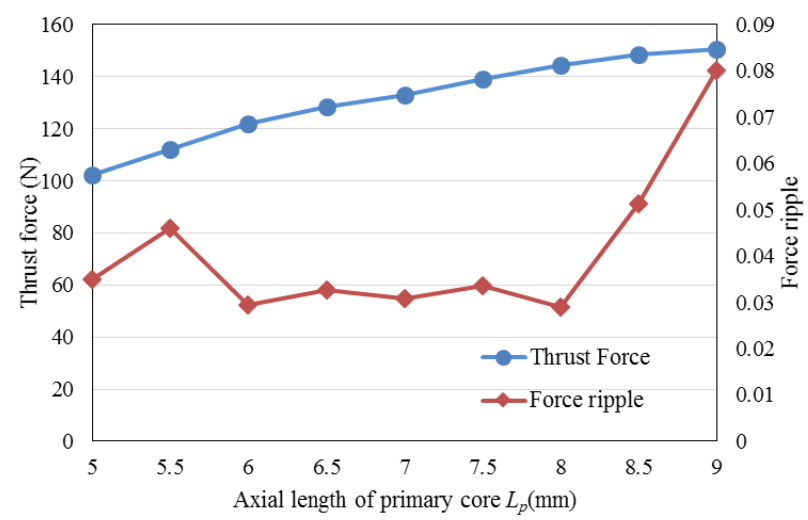

Fig. 9 Thrust force and force ripple of circumferential three-phase FRTFPMLM as a function of different design parameters $L_{p}$

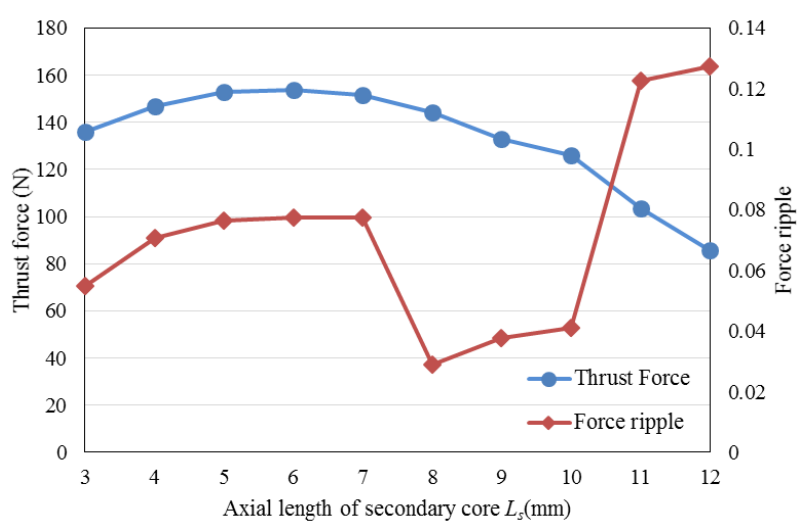

Fig. 10 Thrust force and force ripple of circumferential three-phase FRTFPMLM as a function of different design parameter $L_{s}$

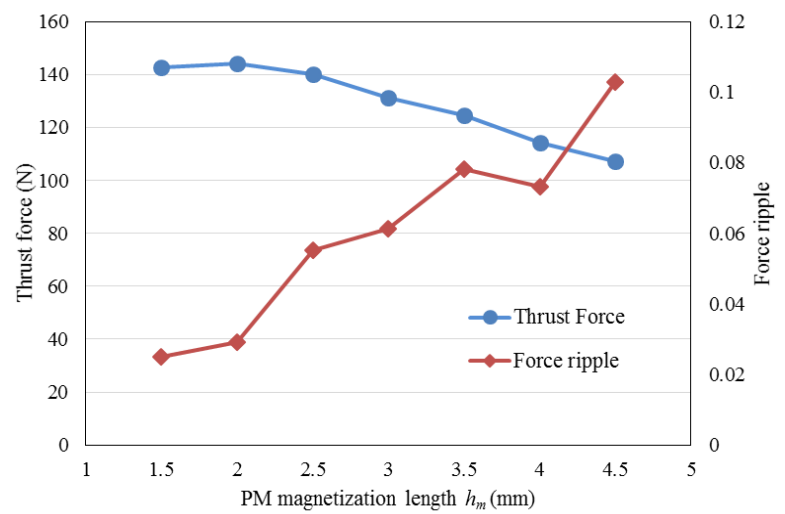

Fig. 11 Thrust force and force ripple of circumferential three-phase FRTFPMLM as a function of different design parameters $\mathrm{h}_{\mathrm{m}}$ 
Fig.9 shows the thrust force and force ripple of the circumferential three-phase FR-TFPMLM as a function of axial length of primary core $L_{p}$ when $L_{\mathrm{s}}$ and $h_{\mathrm{m}}$ is 8 and $2 \mathrm{~mm}$, respectively. It can be seen that the thrust force increases proportionally when $L_{p}$ increases, which is due to the increasing magnetic loading, while force ripple fluctuates, keeping an almost constant minimum value when $L_{p}$ is changing from 6 to $8 \mathrm{~mm}$. The optimal value of $L_{p}$ is $8 \mathrm{~mm}$ which result in a relatively large thrust force and a minimum force ripple.

Fig.10 shows the thrust force and force ripple of the circumferential three-phase FR-TFPMLM as a function of axial length of secondary core $L_{s}$ when $L_{\mathrm{p}}$ and $h_{\mathrm{m}}$ is 8 and $2 \mathrm{~mm}$, respectively. As can be seen, when the secondary core length $L_{s}$ is varied, the thrust force has a peak at $7 \mathrm{~mm}$ and then decreases linearly due to the effect of increasing axial flux leakage. Which becomes more significant than that of increasing the cross area of the main magnetic circuit, while the force ripple fluctuates twice with $L_{s}$ to a minima at $8 \mathrm{~mm}$. From this data, the optimal point is $L_{s}$ of $8 \mathrm{~mm}$, generating a relatively high thrust force and a minimum force ripple.

Fig.11 shows the thrust force and force ripple of the circumferential three-phase FR-TFPMLM as a function of PM magnetization length $h_{m}$ when both $L_{\mathrm{p}}$ and $L_{\mathrm{s}}$ are $8 \mathrm{~mm}$. As with the axial configuration, the winding turn number is decreasing while $h_{m}$ increases due to the reducing slot area, shown in Table II. The maximum thrust force occurs at the point of $2 \mathrm{~mm}$, after which the thrust force decreases linearly, while force ripple increases somewhat proportionally. Considering the magnet demagnetization risk, the $h_{m}$ cannot be too short, so $h_{m}$ of $2 \mathrm{~mm}$ is chosen to achieve a maximum thrust force and a lower force ripple.

In comparison with Fig 6-11, it can be observed that the variation of these three parameters on the average thrust force of both machines are quite similar but there is a significant variation for the force ripple. The optimal length of $L_{\mathrm{p}}$ and $L_{\mathrm{S}}$ for both machines are different, whereas the optimal PM magnetization length $h_{m}$ are the same for both machines.

\section{COMPARISON OF PERFORMANCES OF PROPOSED TWO MACHINES}

The circumferential three-phase FR-TFPMLM is more compact than the axial configuration in terms of mechanical structure, as for the former one the primary cores of the three phases are stacked together. However, as shown in Fig 12, there is an unbalanced magnetic force (UMF) in the circumferential three-phase FR-TFPMLM, whose magnitude is almost equal to that of average thrust force, which will result in a strong mechanical stress on the supporting mechanism and mechanical design challenges, whereas for the axial three-phase FRTFPMLM, no UMF is induced due to symmetry of magnetic circuit.

The performance comparisons of these two optimized topologies and other types of linear motor are summarized in Table III. It can be observed that the thrust force of axial threephase FR-TFPMLM is almost the same as that of the circumferential three-phase FR-TFPMLM but force ripple of the former is $11.1 \%$ lower than that of latter; and the total magnet usage of former one is $14.7 \%$ lower than that of latter one, which makes the former one more advantageous in the aspect of thrust per magnet volume.

On the other hand, the proposed two machines have the same thrust per active air-gap area of $8 \mathrm{kN} / \mathrm{m}^{2}$, which is similar to that of TL-IPM and TR-FRLM, and is 35\% lower than that of FSTFPMLM. For the thrust per magnet volume, both machines are similar to both TR-FRLM and FSTF-PMLM; but are quite advantageous over TL-IPM. However, the thrust force density of proposed machines is much lower than that of TL-IPM, which is a sacrifice for machines with magnets located at the short primary side (space limitation).

TABLE III PERFORMANCES COMPARISON

\begin{tabular}{c|c|c|c|c|c}
\hline \hline & $\begin{array}{c}\text { Axial-FR- } \\
\text { TFPMLM }\end{array}$ & $\begin{array}{c}\text { Circum- } \\
\text { FR- } \\
\text { TFPMLM }\end{array}$ & $\begin{array}{c}\text { TL- } \\
\text { IPM } \\
{[1]}\end{array}$ & $\begin{array}{c}\text { TR- } \\
\text { FRLM } \\
{[12]}\end{array}$ & $\begin{array}{c}\text { FSTF- } \\
\text { PMLM } \\
{[13]}\end{array}$ \\
\hline $\begin{array}{c}\text { Rated thrust } \\
(\mathrm{N})\end{array}$ & 143.3 & 144.3 & 79.4 & 278.6 & 191 \\
$\begin{array}{c}\text { Force ripple } \\
\text { Rated }\end{array}$ & 0.026 & 0.029 & - & - & - \\
$\begin{array}{c}\text { current (A) } \\
\text { Thrust } \\
\text { constant } \\
(\mathrm{N} / \mathrm{A})\end{array}$ & 4 & 4 & 4 & 4 & 8 \\
$\begin{array}{c}V_{t}\left(\mathrm{~cm}^{3}\right) \\
V_{P M}\left(\mathrm{~cm}^{3}\right)\end{array}$ & 18.5 & 36.1 & 19.9 & 69.7 & 23.9 \\
\hline $\begin{array}{c}F_{S} \\
F_{V}\end{array}$ & 8.0 & 848 & 380 & - & 850 \\
$\begin{array}{c}\text { PM thrust } \\
\text { cost }\end{array}$ & 169 & 170.2 & 208.9 & 153.5 & 225.2 \\
$\left(\mathrm{MN} / \mathrm{m}^{3}\right)$
\end{tabular}

Abbreviation:

$V_{P M}$ : PM volume of active part (multiply factor 1.5 for the machine where PM is located in long secondary side).

$F_{S}$ : Thrust force per active air-gap area (unit, $\mathrm{kN} / \mathrm{m}^{2}$ ) [4]

$F_{V}$ : Thrust force per active external volume (unit, $\mathrm{kN} / \mathrm{m}^{3}$ ) [4]

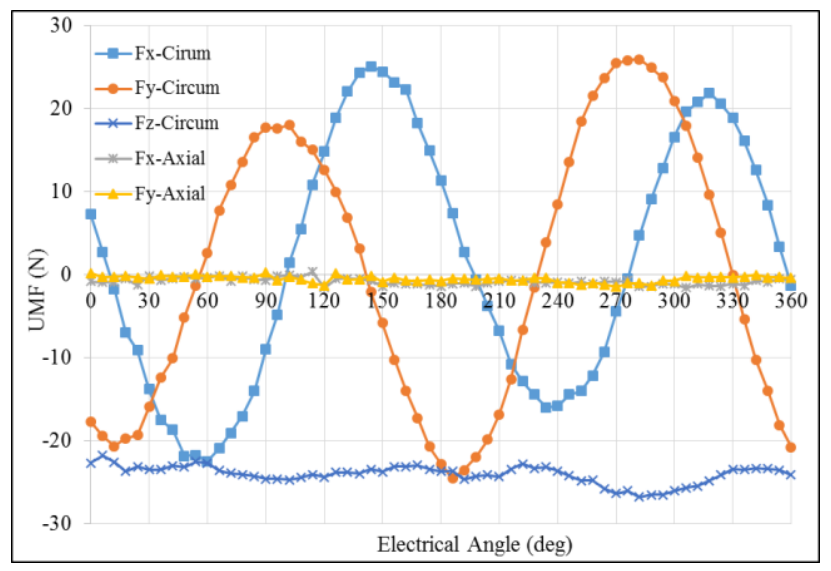

Fig. 12 Unbalanced magnetic force of both machines

\section{CONCLUSIONS}

Two tubular flux-reversal transverse flux PM linear machines: axial three-phase and circumferential three-phase configuration, are proposed in this paper. The theoretical analysis of these two machines is presented with particular 
regard to electromagnetic force, which is useful for preliminary analysis and design, and a simplified model with one pole pair of these two machines for numerical analysis is proposed to save computation time.

The effect of key design dimensions on the electromagnetic performance of these two machines has also been studied. It shows that both machines have the same optimal value of PM magnetization length, while each machine has its own optimal axial length of primary core and of secondary core. At the end, the performances of both machines after optimization are summarized and compared.

It has been found that the circumferential three-phase configuration exhibits almost the same average thrust force as the axial three-phase configuration, and the total magnet usage of the circumferential type is $14.7 \%$ less than that of the axial type. Besides, there is an unbalanced force in the circumferential three-phase FR-TFPMLM, whose magnitude is almost equal to that of average thrust force, which will result in the mechanical stress on the supporting mechanism and bring in mechanical design challenges.

\section{ACKNOWLEDGMENT}

This work is funded by the INNOVATIVE doctoral programme. The INNOVATIVE programme is partially funded by the Marie Curie Initial Training Networks (ITN) action (project number 665468) and partially by the Institute for Aerospace Technology (IAT) at the University of Nottingham.

\section{REFERENCES}

[1] J. Wang and D. Howe, "Design optimization of radially magnetized, iron cored, tubular permanent-magnet machines and drive systems," IEEE Trans. Magn., vol. 40, pp. 3262-3277, 2004.
[2] J. F. Eastham, "Novel synchronous machines: Linear and disc," Electr. Power Applicat., IEE Proc. B, vol. 137, pp. 49-58, 1990.

[3] L. Bertola, T. Cox, P. Wheeler, S. Garvey, and H. Morvan, "lectromagnetic launch systems for civil aircraft assisted take-off," Archives of Electrical Engineering, vol. 64, pp.535-546, 2015.

[4] P. Zheng, S. Zhu, B. Yu, L.M. Cheng, and Y.H. Fan, "Analysis and Optimization of a Novel Tubular Staggered-Tooth Transverse-Flux PM Linear Machine," IEEE Trans. Magn., vol. 21, 8111304, 2015.

[5] N. Bianchi, S. Bolognani, D. D. Corte and F. Tonel, "Tubular linear permanent magnet motors: an overall comparison," IEEE Trans. Ind. Applications, vol. 39, 466-475, 2003.

[6] J. Wang, G.W. Jewell and D. Howe, "A general framework for the analysis and design of tubular linear permanent magnet machines," IEEE Trans. Magn., vol. 35, pp.1986-2000, 1999.

[7] J. Wang and David Howe, "A linear permanent magnet generator for a free-piston energy converter," IEEE International Conference on Electric Machines and Drives, 2005.

[8] J. S. Shin, R. Watanabe, T. Koseki, and H. J. Kim, "Transverse flux type cylindrical linear synchronous motor for large thrust using generic armature cores for rotary machinery," IEEE Trans. Ind. Electron., vol. 61, pp. 4346-4355, 2014.

[9] S. Zhu, P. Zheng, B. Yu, L. Cheng and W. Wang, "Performance analysis and modeling of a tubular staggered-tooth transverse-flux PM linear machine," Energies, vol. 9, 163, 2016.

[10] R. Cao, M. Cheng, W. Hua, W. Zhao and Y. Du, "A new primary permanent magnet linear motor for urban rail transit," in Proc. Int. Conf. Elect. Mach. Syst. (ICEMS), pp. 1528-1532, 2010.

[11] S.U. Chung, H. J. Lee and S. M. Hwang, "A novel design of linear synchronous motor using FRM topology,” IEEE Trans. Magn., vol. 44, pp.1514-1517, 2008.

[12] B. Kou, J. Luo, X. Yang, and L Zhang, "Modeling and Analysis of a Novel Transverse-Flux Flux-Reversal Linear Motor for Long-Stroke Application," IEEE Trans. Ind. Electron. vol. 63, pp. 6238-6248, 2016.

[13] S. Zhu, P. Zheng, and M. Wang, "Design and Optimization of a Novel Flux-Switching PM Linear Machine Used for Electromagnetic Launcher," 18th International Symposium on Electromagnetic Launch Technology (EML), to be published, 2016. 